\title{
A stably cross-linked ink on filter paper with 1D transport for efficient photothermal water treatment
}

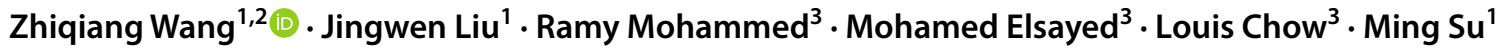

Received: 20 February 2020 / Accepted: 17 September 2020 / Published online: 8 October 2020

(c) Springer Nature Switzerland AG 2020

\begin{abstract}
Photothermal water evaporation using natural solar energy has been attracted more attentions due to wide applications such as water purification, sterilization, power generation and energy conservation. This article reports a low-cost and stable material for efficient generation of water vapor as well as saline and pollution water treatment. The hierarchically porous material consisting of nanoporous carbon and microporous paper is prepared by simply depositing and chemically cross-linking colloidal ink onto a filter paper. A stably homogeneous nanocarbon deposition is formed over microfibers in the paper. The nanocarbon particles greatly increase the surface area of pristine paper (from negligible to $12 \mathrm{~m}^{2} \mathrm{~g}^{-1}$ ) and light absorption. The carbon modified paper allows high water evaporation rate of $1.34 \mathrm{~kg} \mathrm{~h}^{-1} \mathrm{~m}^{-2}$ from a nanoporous carbon film, continuous capillary water transport in the micropores of paper, as well as minimal convective loss to bulk water due to $1 \mathrm{D}$ low contact area with water. The pore sizes of filter papers on the water evaporation together with the controlling of surface temperature and evaporating rate are also performed. Finally, this water solar evaporation system is applied for desalination and wastewater purifying (including heavy metal ion and organic pollutions). A safe freshwater is obtained after treatment. This study demonstrates the potential application of chemical modification of inked filter paper to achieve high evaporation rate and efficiency by rational design.

Graphic abstract A low-cost and stable material for efficient generation of water vapor and wastewater treatment was brought out, which is prepared by simply depositing and cross-linking colloidal ink onto a filter paper. The carbon modified paper allows efficient light absorption, high water evaporation rate from a nanoporous carbon film, continuous capillary water transport in the micropores of paper, as well as minimal energy loss.
\end{abstract}

\section{Electronic supplementary material The online version of this article (https://doi.org/10.1007/s42452-020-03556-7) contains} supplementary material, which is available to authorized users.

$\triangle$ Ming Su, m.su@northeastern.edu| 1 Department of Chemical Engineering, Northeastern University, 313 Snell Engineering Center, 360 Huntington Avenue, Boston, MA 02115, USA. ${ }^{2}$ Tianjin Key Laboratory of Water Environment and Resources, Tianjin Normal University, Tianjin 300387, China. ${ }^{3}$ Department of Mechanical and Aerospace Engineering, University of Central Florida, Orlando, FL 32826, USA. 


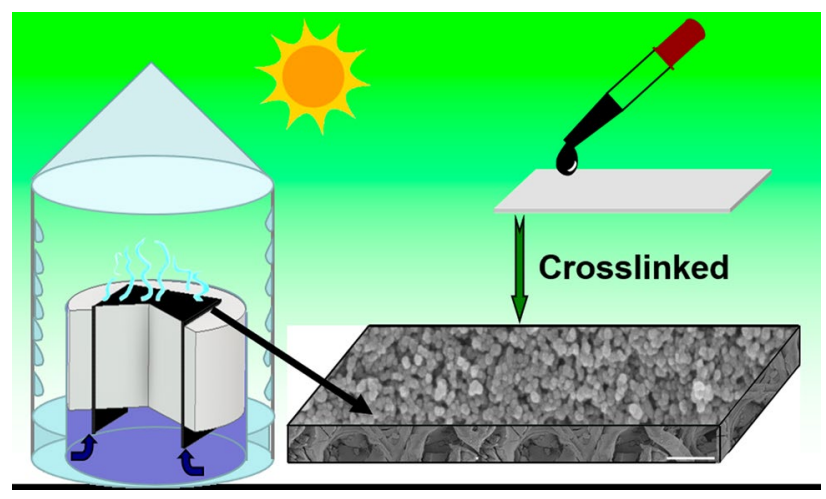

Keywords Pollution treatment · Solar evaporation · Desalination · Cross-linked

\section{Introduction}

Photothermal water evaporation is important process for its broad range of applications, such as desalination, power generation, absorption cooling, water purification and sterilization [1-8]. Current techniques of water evaporation with solar energy have low efficiency [9-12]. Although concentrating the heat can accelerate this process, it needs large surface and much equipment $[13,14]$. Selective heating of air-water interface with unfocused natural solar energy has been used to enhance water evaporation, where water evaporation is facilitated by locating the energy at the air-water interface with a material (metal, semiconductors or carbon materials) that has strong light absorbing ability and good porosity [15-21]. The strong light absorbing materials can efficiently convert solar energy into heat, and the porous materials with wicking ability allow continuous transport of liquid water to the evaporating surface $[22,23]$. A variety of carbon materials including nanotubes, graphene, graphene oxide and carbon powder with porous structure and strong light absorption in the visible to near-infrared regions have also been used for thermal evaporation and purification of water with [24-30]. However, these porous materials are limited by their non-optimized structures, high-cost (metal and semiconductor), poor availability at large quantity (nanotube and graphene), materials loss during operation and low hydrophilicity [31-33]. More recently, the cheaper carbon ink deposited on different porous materials is used for the application in the solar evaporation [34], while the stability of materials and the effect of pore size on the evaporation are not investigated.

Herein, the nanoporous carbon film is produced on different size microporous filter paper by depositing colloidal ink used for printers, followed by glutaraldehyde cross-linking with aldol condensation to improve its stability in water. Glutaraldehyde has two highly active aldehyde groups, which are widely applied for cross-linking organic compounds or polymers containing hydroxyl groups. Due to the uniform size distribution, a homogeneous nanoporous carbon film is formed on the cellulous microfibers in the paper. Other than the benefits associated with low cost and wide availability, the hierarchical porous material allows complete absorption of visible-toinfrared light, efficient water evaporation due to large surface area enabled by nanopores, continuous rapid transport of water through micropores during operation and minimal convective loss to bulk water due to 1D contact area with water (Scheme 1). An energy efficiency of $90 \%$ with evaporation rate of $1.34 \mathrm{~kg} \mathrm{~m}^{-2} \mathrm{~h}^{-1}$ for pure water has been achieved on modified paper with pore size of $25 \mu \mathrm{m}$ at an incident energy intensity of $1 \mathrm{~kW} \mathrm{~m}^{-2}$. We also found a relationship between evaporating rate and evaporating surface temperature. Following this relationship, we try to control the steam temperature and the evaporating rate by changing the experimental conditions. It was also explored to saline water and polluted water treatment, and safe freshwater was obtained after photothermal membrane purifying. This study may benefit the further researches and applications of photothermal water treatment materials.

\section{Experimental}

\subsection{Materials}

Water-based matte black ink for Epson piezo inkjet printers was purchased from Nano Digital. The ink is stable and has a solid content of about $6.6 \mathrm{wt} \%$ and a reported shelf 


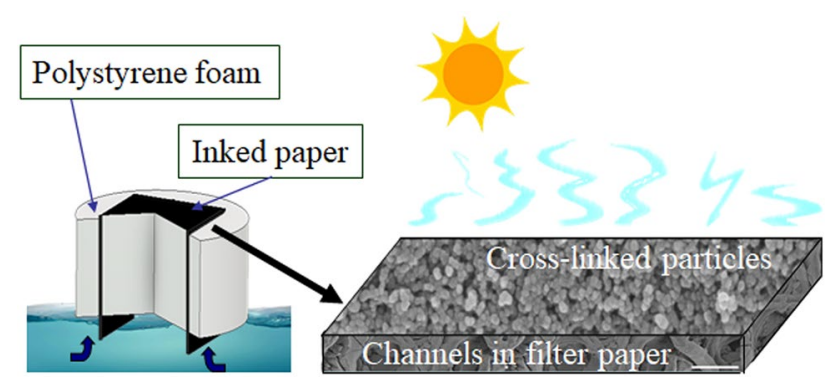

Scheme 1 The schematic diagram of photothermal evaporation on carbon nanoparticles modified filter paper

life of 2 years. Cellulose filter papers (thickness of $180 \mu \mathrm{m}$ ) were obtained from VWR at three Whatman grades: grade 1 (pore size $11 \mu \mathrm{m}$ ), grade 4 (pore size $25 \mu \mathrm{m}$ ) and grade $5(2.5 \mu \mathrm{m})$. The glutaraldehyde used for cross-linking carbon nanoparticles with cellulose microfibers was from Alfa-Aesar.

\subsection{Black ink modifying of the filter papers}

The filter papers, $7.0 \mathrm{~cm}$ in diameter, were modified as follows: two glass plates were used. Firstly, placing one glass plate on a flat surface, after putting on a filter paper, one drop of ink was added. Then, quickly covering the other plate and applying pressure evenly, after drying at $60^{\circ} \mathrm{C}$ for $3 \mathrm{~h}$, the inked paper was immersed in an aqueous solution of $10 \%$ (weight percent) glutaraldehyde and $0.05 \mathrm{ml}$ of dilute hydrochloric acid ( $1 \mathrm{M}$ ) at $50^{\circ} \mathrm{C}$ for $2 \mathrm{~h}$; after washing by deionized water, the black color filter paper with cross-linked carbon powders was dried at $60^{\circ} \mathrm{C}$ for $12 \mathrm{~h}$. The amount of water taken on modified paper was determined as follows: the paper was immersed in deionized water for $1 \mathrm{~min}$, followed by filtration removal of excess water on the surface; the percentage of water uptake was determined from the weight of wet paper and that of dried paper. The rate of water transport in a paper was determined by putting one side of the paper in blue inked water and measuring the height of colored contact line climbing on the paper over time.

\subsection{Characterization}

The ink modified filter paper was characterized by the following techniques. X-ray diffraction (XRD) was performed using a powder $X$-ray diffractometer (Rigaku) employing $\mathrm{Cu} \mathrm{Ka}$ radiation at accelerating voltage of $40 \mathrm{kV}$ and beam current of $40 \mathrm{~mA}$. The surface area was measured with single-point Brunaeur-Emmett-Teller (BET) method using a Nova 2010E instrument (Nova). The micro- and nanostructures were imaged in secondary electron mode after sputter-coating a thin layer of platinum using a Zeiss scanning electronic microscope (Ultra 55 SEM) operated at accelerating voltage of $10 \mathrm{keV}$. The chemical compositions of paper before and after modification were examined with a PerkinElmer Fourier transform infrared (FTIR) spectrometer. The mechanical strengths of paper before and after modification were measured with a mechanical test instrument (Electro Force 3200, TA Instruments) at $0.08 \mathrm{~mm} \mathrm{~s}^{-1}$ tensile velocity. The optical absorption of paper was measured using an Ocean Optics mini-spectrometer with a halogen lamp. The temperatures were monitored by using a thermocouple, and the thermal images were obtained by an IR camera (FLIRT450 se) with temperature accuracy of $\pm 1^{\circ} \mathrm{C}$.

\subsection{The test of photothermal evaporation performance}

The photothermal evaporation of water from a hierarchical porous paper was examined with an infrared heater ( $250 \mathrm{~W}$ tungsten lamp) to simulate solar irradiation. The light intensity was controlled at $1 \mathrm{~kW} \mathrm{~m}^{-2}$ (one sun) by adjusting the voltage applied to the lamp. A filter paper cut to a dimension of $6.5 \mathrm{~cm}$ long and $2.1 \mathrm{~cm}$ wide was fixed through two slits made on a polystyrene block (white) floating on water, where two ends of rectangular paper touch the water and provide a path for continuous water transport to the paper area between the two slits via capillary action. The hydrophobic polystyrene block avoids heat loss from the paper to bulk water (Scheme 1). The whole setup was placed inside a high precision electronic balance, which is connected to a computer to monitor the mass change of paper over time. The door to the balance was opened slightly to ensure the humidity inside balance is close to that in ambient condition (temperature of $23^{\circ} \mathrm{C}$, pressure of $1 \mathrm{~atm}$ and relative humidity of $50 \%$ ). The water evaporation rate was derived from the rate of mass loss over time per unit of the surface area of absorber film facing the light.

\subsection{Saline water and polluted water treatment}

A saline water with three normal ions $\left(\mathrm{Na}^{+}, \mathrm{Ca}^{2+}\right.$ and $\left.\mathrm{Mg}^{2+}\right)$ was used for desalination. And a solution containing heavy metal ion $\mathrm{Cr}^{6+}$ was used for pollution treatment. Besides, the removal of persistent organic pollutant chlorophenol with a concentration of $10 \mathrm{mg} \mathrm{L}^{-1}$ was also carried out. In a typical experimental, the cross-linked nanoink-dyed filter paper membrane was immersed in the above solution, respectively, under the solar irradiation of $1000 \mathrm{~kW} \mathrm{~m}^{-2}$. The beaker was placed in a container with a circular cone polythene film on the top for condensation steam after evaporation. The concentrations of these ions in water before and after treatment were detected by the ICP-AES. The chlorophenol concentration in the water was analyzed 
by Fuli 9790 gas chromatography using a flame ionization detector (FID) according to Chinese National Standard (GB/T 5750.10-2006) for chlorophenol. Briefly, the sample was firstly extracted by a mixture of cyclohexane and ethyl acetate, and then the chlorophenol was converted to ester by adding acetic anhydride using pyridine as the catalyst. The polluted water samples with different $\mathrm{pH}$ values were also tested, which were adjusted by $0.01 \mathrm{M} \mathrm{NaOH}$ or $0.01 \mathrm{M}$ $\mathrm{HCl}$ solution.

\section{Results and discussions}

\subsection{The fabrication and characterization of ink-dyed filter paper}

Glutaraldehyde is used to cross-link the carbon nanoparticles in ink to the cellulose microfibers in a native porous filter paper (Scheme S1). Figure 1a shows the FTIR spectra of a pristine filter paper and an ink-dyed filter paper before and after cross-linking. The characteristic band at $3300 \mathrm{~cm}^{-1}$ is from O-H vibration of hydroxyl group. After ink staining, the intensity of band at $3300 \mathrm{~cm}^{-1}$ increases because carbon nanoparticles in ink have $-\mathrm{OH}$ groups.
After cross-linking, the intensity of this band decreases, and a new band at $1530 \mathrm{~cm}^{-1}$ assigned to $C=O$ vibration of carbonyl group appears, indicating glutaraldehyde reacts with carbon nanoparticles and cellulose. The dried ink pellet and inked filter paper are analyzed by XRD (Figure S1), where two broad peaks at 24 and 44 degrees are attributed to the (002) and (100) crystalline planes of graphite phase, respectively. The crystalline size of dried ink is determined to be $0.94 \mathrm{~nm}$ using the Debye-Scherrer formula with full width at half maximum (FWHM) for the peak at $24^{\circ}$. In comparison, only characteristic peaks belonging to cellulose can be observed in the XRD patterns of the inked filter paper, which is likely due to highly diluted nature of carbon nanoparticles on filter paper. The carbon nanoparticles cross-linked onto paper are stable when immerged in water (Fig. 1b left), where the paper remains black and the solution remains clear over 1 week (Figure S2), confirming strong attachment of carbon nanoparticles to the cellulose fibers. In comparison, the paper with no crosslinked ink (Fig. 1b right) loses black color immediately once immersed in water. After cross-linking, glutaraldehyde reacts with hydrophilic hydroxyl groups. The hydrophilicity is reduced, while the contact angle to water increases (Figure S3). Cross-linking also enhances the mechanical
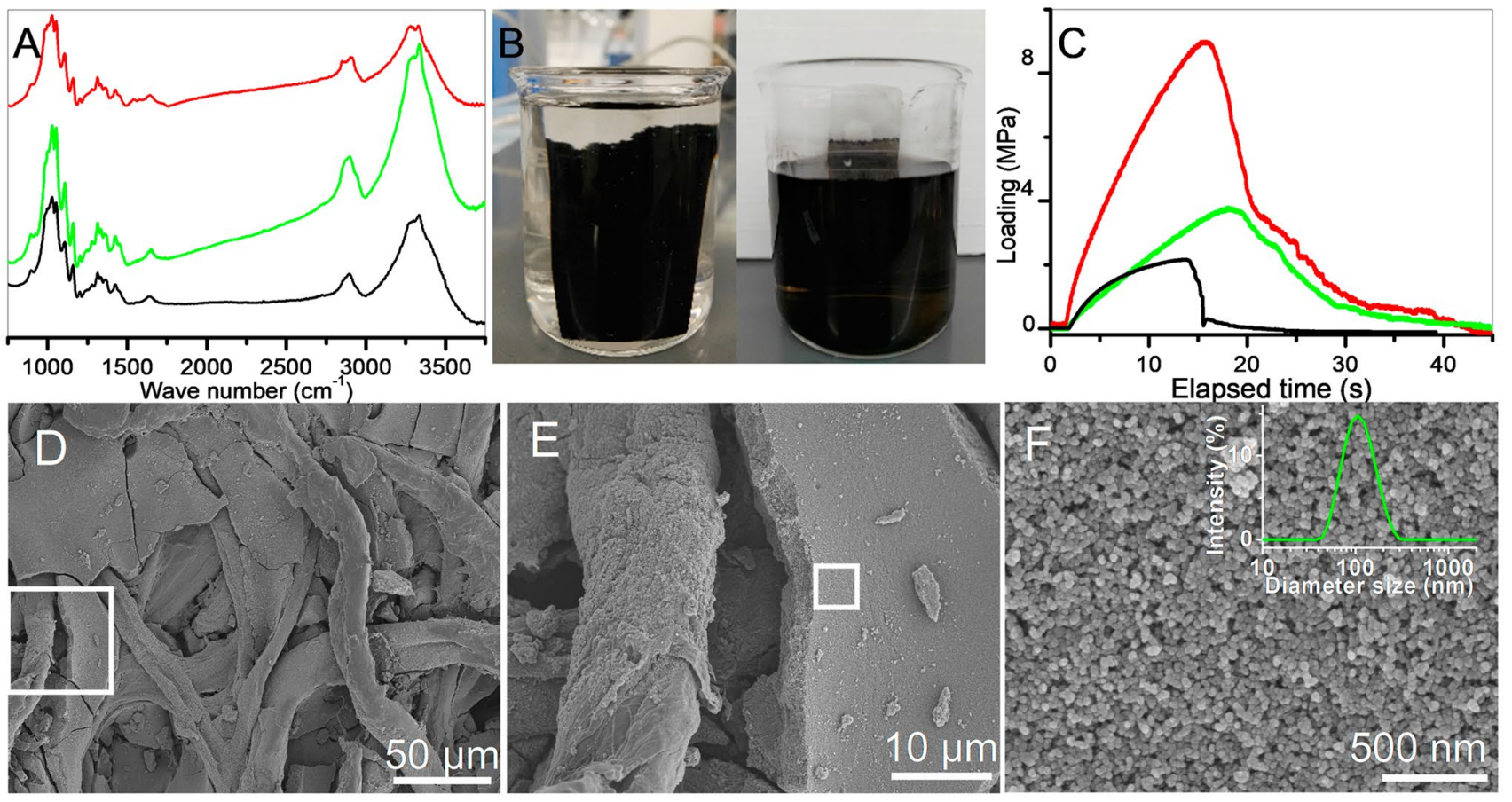

Fig. 1 FT-IR spectra (a) of pristine paper (black), ink stained paper (green) and paper with cross-linked carbon nanoparticles (red); mechanical strengths (b) of pristine paper (black), ink stained paper (green) and paper with cross-linked carbon nanoparticles (red); the digital images of paper (c) with cross-linked carbon nanoparticles (left) and non-cross-linked carbon nanoparticles (right) after immersing in water; SEM images of carbon nanoparticle modified paper with $25 \mu \mathrm{m}$ pore size, where the image magnificence increases from $\mathbf{d}$ to $\mathbf{f}$, and the white square in each image is zoomed in the next image; DLS curve (f inset) of carbon nanoparticles in water diluted ink

\section{SN Applied Sciences}


strength of paper (Fig. 1c), where the Young's modulus of paper with cross-linked ink is 2 times higher than those of pristine paper and paper with non-cross-linked ink. The fracture strength of paper with cross-linked ink is 2 times higher than paper with non-cross-linked ink. The excellent mechanical strength of paper after ink cross-linking is likely due to the formation of cross-linked network within cellulous microfibers, which ensures a longer operating life of paper. Figure S4 shows the SEM image of ink modified filter paper with reported pore size of $25 \mu \mathrm{m}$ at low magnification. It can be seen that the cellulous microfibers span the whole paper sample with length over millimeters. In an enlarged region, a dense ink film can be observed with a thickness of $1-2 \mu \mathrm{m}$ (Fig. 1d). Further zooming into the dense film reveals its smooth surface, and eventually individual ink nanoparticles can be found in further enlarged image (Fig. 1e, f). The diameter of each particle with nearly spherical shape is approximately $50-70 \mathrm{~nm}$ which is close to the hydrodynamic diameter $(100 \mathrm{~nm})$ of ink particles in highly diluted solution (Fig. $1 \mathrm{f}$ inset). The increased hydrodynamic diameter is likely due to extended polymer surfactant or swelling particles in solvent. $\mathrm{N}_{2}$ adsorption and desorption measurement shows the surface area dramatically increases from below 1 to $11.9 \mathrm{~m}^{2} \mathrm{~g}^{-1}$ due to the nanopores (average size of $3.8 \mathrm{~nm}$ and pore volume of $0.059 \mathrm{~mL} \mathrm{~g}^{-1}$ ) generated after modification (Figure S5). The liquid ink contains $6.6 \%$ of solid (mostly carbon nanoparticles) after complete drying for $12 \mathrm{~h}$ at $120^{\circ} \mathrm{C}$. Thermogravity analysis shows a $3 \%$ mass loss below $100{ }^{\circ} \mathrm{C}$ due to release of water, a $8 \%$ mass loss from 180 to $340{ }^{\circ} \mathrm{C}$ due to removal of organic additives and a $15 \%$ mass loss from 340 to $400{ }^{\circ} \mathrm{C}$ due to graphite decomposition or graphite defunctionalization (Figure S6).

\subsection{Photothermal properties of the inked paper}

Figure 2a shows the reflection and transmission spectra of paper and carbon nanoparticle modified paper. The optical absorption of dry pristine paper is about 50 to $85 \%$ at the measured wavelength range, which is relatively low because of its smoothness and white color, while that of dry ink modified paper increases to nearly $100 \%$. The surface temperature measurement confirms enhanced light absorption under one sun light, where the surface temperature of dry modified paper reaches $56.5^{\circ} \mathrm{C}$ after light exposure for $120 \mathrm{~s}$ (Fig. 2b). In contrast, the surface temperature of dry pristine paper only reaches $30.2^{\circ} \mathrm{C}$ after exposure under the same condition (Fig. 2C). The stable temperature can reach $66.1^{\circ} \mathrm{C}$ on modified paper after prolonging irradiation, which is much higher than that $\left(36.2^{\circ} \mathrm{C}\right.$ ) of pristine paper (Fig. $2 \mathrm{~d}$ ). The surface temperature of modified paper in the presence of water is determined to be $33.2{ }^{\circ} \mathrm{C}$ at the same condition (Fig. 2e). The photothermal property of bulk water is also determined,
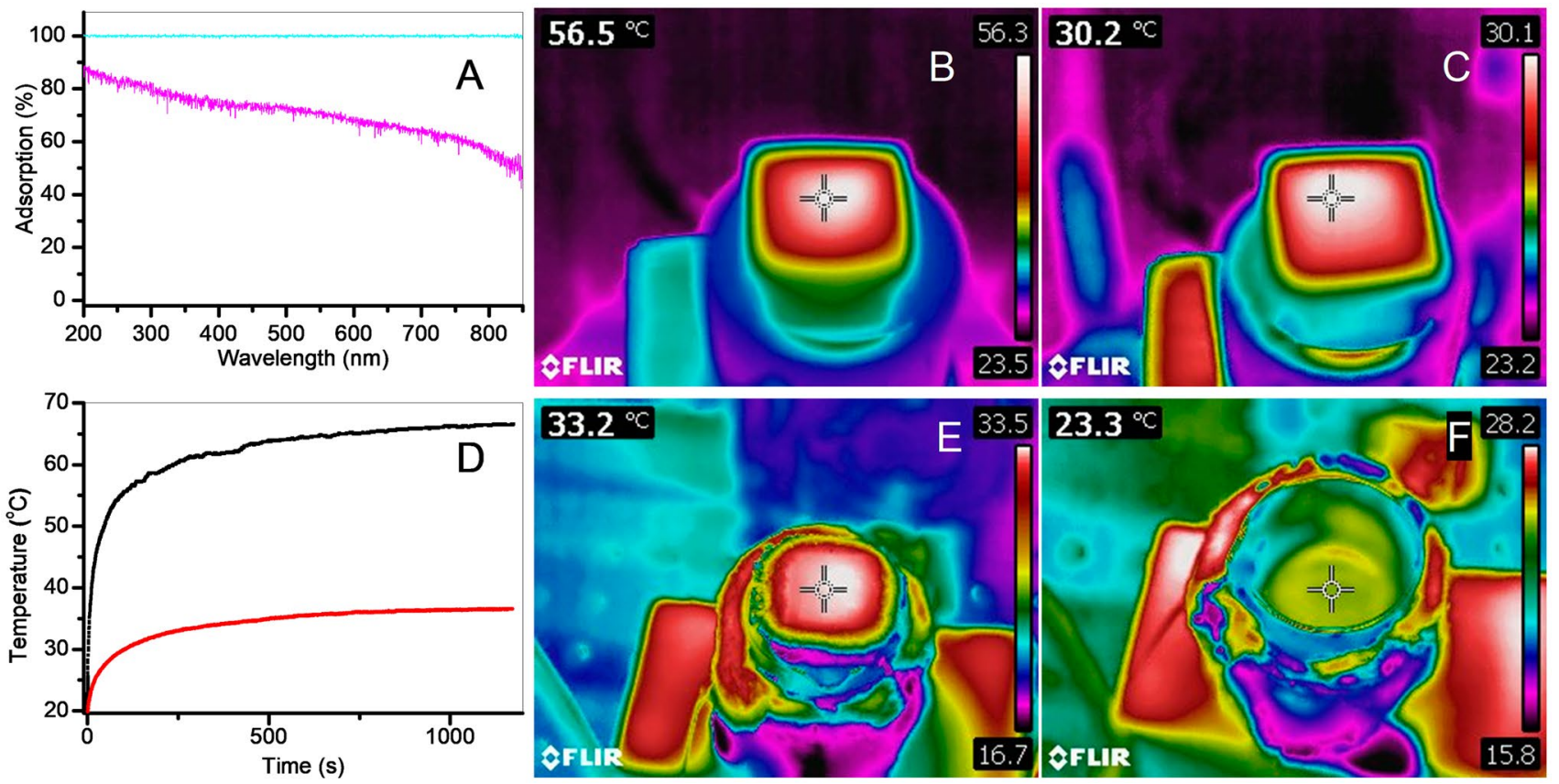

Fig. 2 Optical absorption (a) of pristine paper of $25 \mu \mathrm{m}$ pore size (pink) and carbon nanoparticle cross-linked paper (Cyan); thermal images of carbon nanoparticle cross-linked paper (b) and pristine paper (c) after exposure to $1 \mathrm{~kW} \mathrm{~m}^{-2}$ light for $120 \mathrm{~s}$; surface tem- peratures (d) of paper (red) and carbon nanoparticle cross-linked paper (black); thermal images of wet carbon nanoparticle crosslinked paper (E) and bulk water (f) after exposure to $1 \mathrm{~kW} \mathrm{~m}^{-2}$ light for $120 \mathrm{~s}$ 
where $30 \mathrm{ml}$ of water that forms a $2.4-\mathrm{cm}$ high column in a 3.9-cm-diameter beaker achieves a temperature rise from 19.9 (measured at water surface with a thermocouple) to $23.3^{\circ} \mathrm{C}$ (Fig. 2f). The modified paper absorbs more heat in comparison with bulk water.

\subsection{Photothermal evaporation performance of the black filter paper}

Figure 3a (up) shows the time-dependent weight loss of carbon nanoparticle modified paper with pore size of $25 \mu \mathrm{m}$ (SEM image of filter paper is inset), where the two terminals of the rectangular paper are immersed $5 \mathrm{~mm}$ in water, and water climbs up to wet the paper due to capillary action. The weight loss is slow at the initial stage until the curve reaches a constant slope. Figure $3 a$ (down) indicates that the evaporation surface temperature is low initially and quickly reaches equilibrium within $60 \mathrm{~s}$. The rate of water evaporation is determined from the slope of weight loss versus time curve for three energy intensities $\left(1,2.7\right.$ and $\left.7 \mathrm{~kW} \mathrm{~m}^{-2}\right)$. Both water loss and the surface temperature increase when the incident energy intensity increases from 1 to $7 \mathrm{~kW} \mathrm{~m}^{-2}$. At $1 \mathrm{~kW} \mathrm{~m}^{-2}$, the rate of water evaporation from the modified paper is much higher than those from pristine paper $\left(0.56 \mathrm{~kg} \mathrm{~m}^{-2} \mathrm{~h}^{-1}\right)$ (Figure S7) and bulk water $\left(0.31 \mathrm{~kg} \mathrm{~m}^{-2} \mathrm{~h}^{-1}\right)$ (Fig. 3b) with evaporating surface area of $11.9 \mathrm{~cm}^{2}$ and depth of $2.4 \mathrm{~cm}$. And the surface temperature of bulk water increases slowly than that of carbon modified paper which is due to the heating of the whole body of water in the latter case.

Filter papers with different pore sizes have been modified with carbon nanoparticles following the same procedure. The optical absorptions on these three papers are same (Fig. 2a and Figure S8). Figure 3c, d shows timedependent water evaporation from carbon nanoparticle modified paper with a pore size of 11 and $2.5 \mu \mathrm{m}$, respectively. The evaporation rate from paper with a small pore is lower than that from paper with a large pore at the same energy intensity. For example, the evaporation rate from $25 \mu \mathrm{m}$ paper $\left(1.34 \mathrm{~kg} \mathrm{~m}^{-2} \mathrm{~h}^{-1}\right)$ is higher than that from $2.5 \mu \mathrm{m}$ paper $\left(1.21 \mathrm{~kg} \mathrm{~m}^{-2} \mathrm{~h}^{-1}\right)$ at energy intensity of $1 \mathrm{~kW} \mathrm{~m}^{-2}$. Water evaporation rate increases with energy

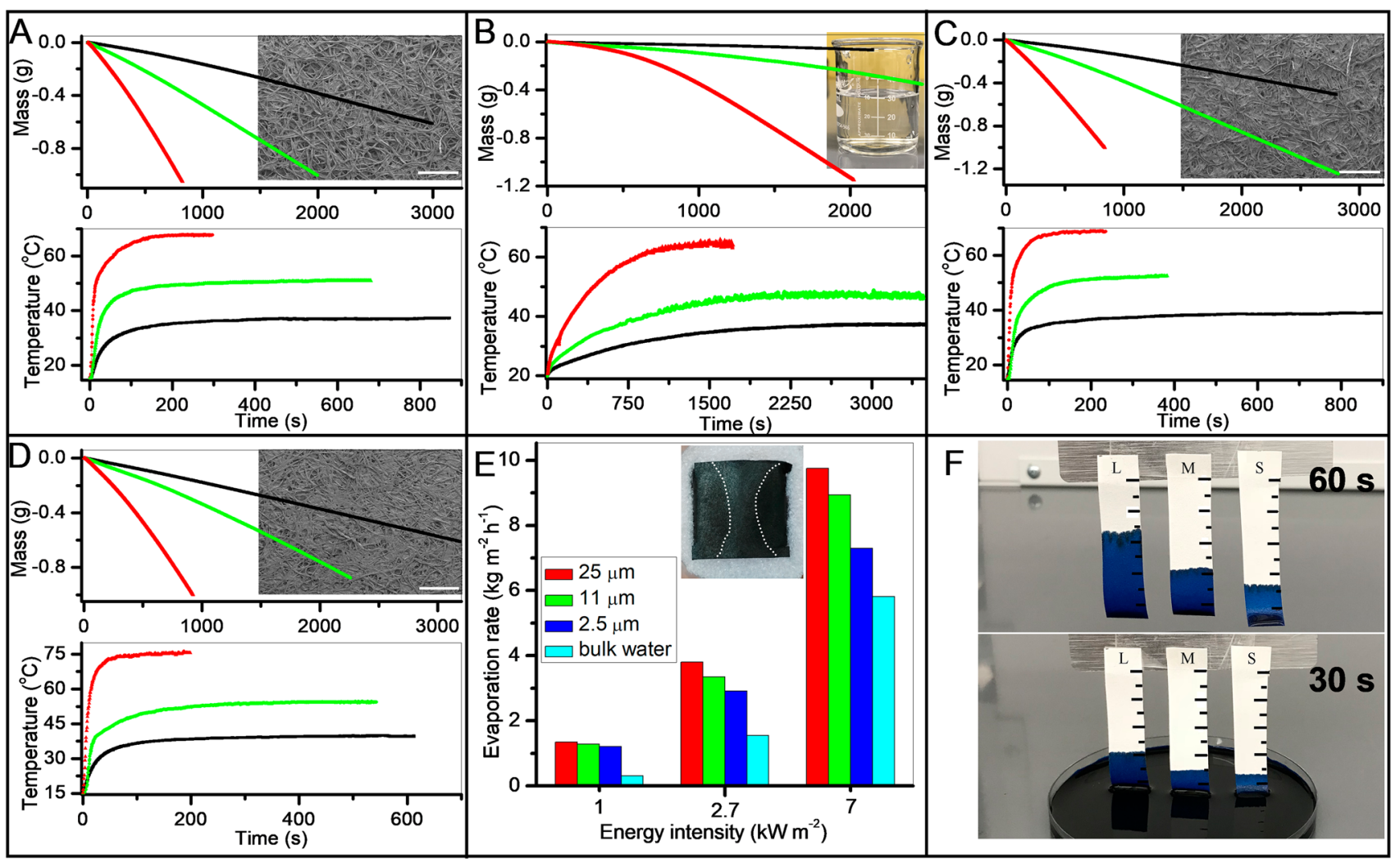

Fig. 3 Weight loss (up) and surface temperature (down) of carbon nanoparticle cross-linked paper after exposure to light of different intensities (black for $1 \mathrm{~kW} \mathrm{~m}^{-2}$, green for $2.7 \mathrm{~kW} \mathrm{~m}^{-2}$, and red for $7 \mathrm{~kW} \mathrm{~m}^{-2}$ ), where $\mathbf{a}, \mathbf{C}$ and $\mathbf{d}$ are for papers with pore size of 25,11 and $2.5 \mu \mathrm{m}$, respectively, which is compared to those of bulk water exposed at the same conditions (b); inset images are SEM images of paper (a, $\mathbf{c}$, and $\mathbf{d}$ ), and digital image of water in beak (b); water evaporating rates from carbon nanoparticle modified papers of different pore sizes (e) in comparison with that of bulk water; digital images (f) of blue colored water climbing up different papers at $30 \mathrm{~s}$ (down) and $60 \mathrm{~s}$ (up)

\section{SN Applied Sciences}


intensity for both pore sizes; however, the ratio of the increase is higher at higher energy intensity (Fig. 3e and Table S1). The ratio of the evaporating rate at $7 \mathrm{~kW} \mathrm{~m}^{-2}$ to the evaporating rate at $1 \mathrm{~kW} \mathrm{~m}^{-2}$ on $2.5 \mu \mathrm{m}$ paper is 6.0 , which is much lower than the ratio of 7.3 on $25 \mu \mathrm{m}$ paper and of 7.0 on $11 \mu \mathrm{m}$ paper. These results are due to water transport difference, where water transport in the small pore sized paper does not meet the requirement at the high evaporation rate. This point is supported by an image showing a dried middle section at $7 \mathrm{~kW} \mathrm{~m}^{-2}$ after 15 min of exposure (Fig. 3e inset), meaning that paper with small pores may not be suitable for water evaporation at high energy intensity due to the limited water transport. The water adsorption and transport on different pore size filter papers are studied (Fig. 3f). It can be seen at 30 and $60 \mathrm{~s}$, the heights of water are highest on the paper with a pore size of $25 \mu \mathrm{m}$, and its water transporting rate is $0.44 \mathrm{~mm} \mathrm{~s}^{-1}$, which is almost three times that of the filter paper with the smallest pore size of $2.5 \mu \mathrm{m}$; meanwhile, the large pore paper shows higher water adsorption (70.5\%) than the smaller pore size papers (66.2\% for $11 \mu \mathrm{m}$ and $57.3 \%$ for $2.5 \mu \mathrm{m}$ ). Both the water transport speed and amount of water absorption indicate that the large pore size filter paper has a high porosity and favors water transport. These results are consistent with the SEM results.

\subsection{The recycle of water evaporation on cross-linked inked filter paper}

Four parallel water evaporation tests were carried out on 25 um inked filter paper with light intensity of $1 \mathrm{~kW} \mathrm{~m}^{-2}$, and the results are shown in Fig. 4. At the same time, the evaporation rate was calculated according to the weight loss. It can be seen from the result, the error of evaporation rate is less than $3 \%$, and the temperature error is less than
$0.5 \%$. It shows that the water evaporation on this device has good repeatability under the test condition.

\subsection{Temperature and efficiency analysis}

Figure 4a shows the evaporation results on the different pore size paper at $1 \mathrm{~kW} \mathrm{~m}^{-2}$, it can be seen the water evaporation rate on three filter paper is fast on filter paper with the larger pore size (from 2.5, 11 to $25 \mu \mathrm{m}$ ). In contrast, the steady surface temperature decreases from $39.7,38.8$ to $37.4^{\circ} \mathrm{C}$. These results can be explained by the following formulas and analysis.

The total heat loss consists of convective loss to air $\left(Q_{\text {Con }}\right)$, radiative loss to air and enclosure $\left(Q_{R}\right)$ and conductive loss $\left(Q_{\text {Cond }}\right)$ to water. Here, the conductive loss can be negligible due to the minimal contract to the bulk water through one-dimensional water transport (Scheme 1). $Q_{\text {Con }}$ and $Q_{R}$ can be derived with:

$Q_{\text {Con }}=h A\left(T-T_{\mathrm{m}}\right)$

$Q_{\mathrm{R}}=\varepsilon A \sigma\left(T^{4}-T_{\mathrm{e}}^{4}\right)$

(where $h$ is the convective heat transfer coefficient of air $\left(10 \mathrm{~W} \mathrm{~m}^{-2} \mathrm{~K}^{-1}\right), \varepsilon$ is the emissivity (0.9), $\sigma$ is Stefan-Boltzmann constant $\left(5.67 \mathrm{e}^{-8} \mathrm{~W} \mathrm{~m}^{-2} \mathrm{~K}^{-4}\right), A$ is the surface area of absorber film facing the light $\left(4.83 \times 10^{-4} \mathrm{~m}^{2}\right), T$ is the temperature of surface, $T_{\mathrm{m}}$ is temperature of conductive layer that can be derived as the mathematic average of evaporating and environmental temperatures, and $T_{\mathrm{e}}$ is temperature of irradiation environmental). Both heat loss $Q_{\text {Con }}$ and $Q_{R}$ increase with surface temperature $T$ raising. Considering that solar energy consists of heat loss and energy for water evaporation (Eq. 3), the energy efficiency will be lower under higher surface temperature. Meanwhile, the relationship of efficiency of energy and water evaporation rate can be shown in Eq. 4 [35].
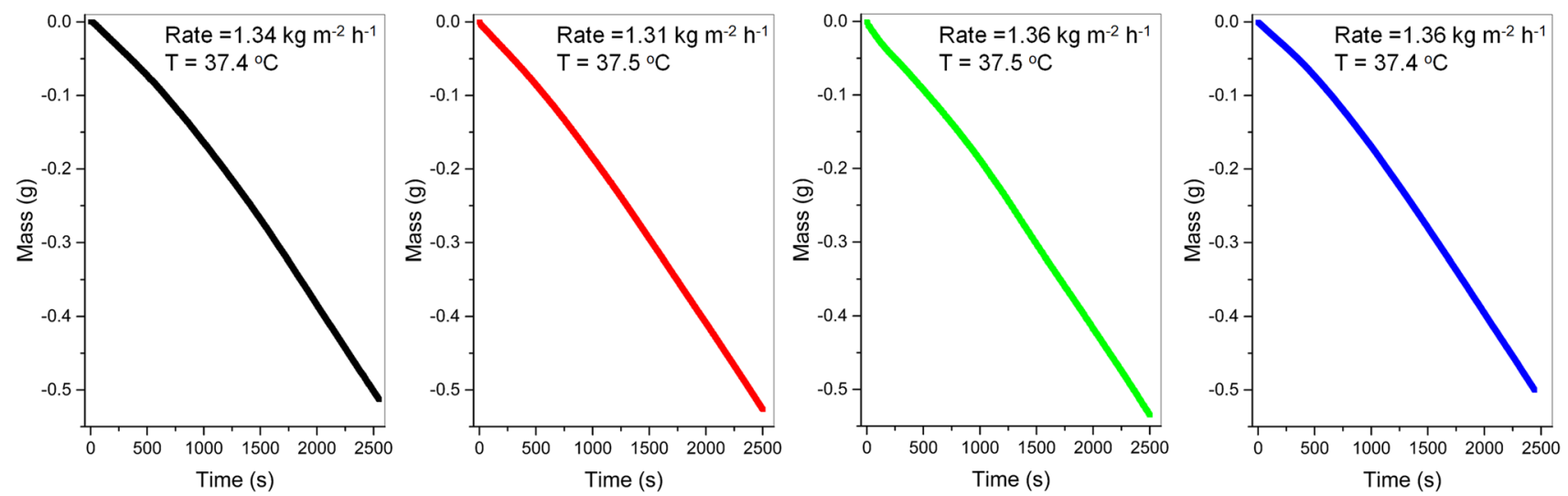

Fig. 4 The recycle of water evaporation on cross-linked inked filter paper 
$\eta=1-\frac{\text { heat loss }}{\text { solar energy }} \times 100 \%$

$\eta=\frac{v_{\mathrm{e}} \times H_{\left(\mathrm{Evap}, T_{0}\right)}+v_{\mathrm{e}} \times C_{\mathrm{p}(\mathrm{H} 2 \mathrm{O}, \mathrm{g})} \times\left(T-T_{0}\right)}{\text { solar energy }} \times 100 \%$

(where $T_{0}$ is room temperature, $v_{\mathrm{e}}$ is water evaporation, $C_{\mathrm{p}(\mathrm{H} 2 \mathrm{O}, \mathrm{g})}\left(1.85 \mathrm{~kJ} \mathrm{~kg}^{-1} \mathrm{~K}^{-1}\right)$ is the constant pressure heat capacity of gaseous water and $H\left(2446 \mathrm{~kJ} \mathrm{~kg}^{-1}\right)$ is evaporation enthalpy of water at room temperature). For calculation convenience, some adjustments have been made to the formula. Because the evaporation enthalpy of liquid water at different temperatures is not a constant value and the enthalpy is a state function, we adopt a constant enthalpy that the evaporation enthalpy of water at room temperature. (The detailly deducing process can be found in Figure S9.) It can be seen from these formulas, when the surface temperature is higher, the efficiency of energy is lower. Accordingly, the evaporation rate is slower. In other words, one can expect an extreme condition that if the heat loss is forbidden, then the evaporation surface temperature was same to the room temperate, and at this condition the solar energy is completely used for water evaporation, so the energy effective is highest and the evaporation rate is fastest. On the other hand, if the solar energy is all for heat loss, and the water evaporation is avoided (membrane is coated by a transparent polyethylene) and the energy effective is zero, then the surface temperature is highest. It should be noted that this trend is general for water evaporate, no matter what material is the membrane. For the conductive loss $\left(Q_{\text {cond }}\right)$ to water is not included here, it is an ideal condition. This balance of surface temperature and evaporation rate is depicted in Fig. 4b. Compared to the literature (Table S2), this crosslinked ink on filter paper has a really low temperature $\left(37.4^{\circ} \mathrm{C}\right.$ ) for water evaporation. Thus, a high energy utilization efficiency was achieved. We also try to increasing the surface temperature by decreasing the evaporating rate, which is obtained through covering the inked filter paper with pore size of $25 \mu \mathrm{m}$ by a thin transparent polyethylene film $(15 \mu \mathrm{m})$ with perforated pores, which is assumed not affecting heat releasing. (The IR image is shown in Figure S10.) The evaporation result is also represented in Fig. 5a, which also proves decreasing evaporating rate resulting in a higher surface temperature. The higher temperature steam is favorite for some applications such as power generation and sterilization.

\subsection{Solar desalination and wastewater treatment}

The desalination results of saline water with three primary ions $\left(\mathrm{Na}^{+}, \mathrm{Ca}^{2+}\right.$ and $\left.\mathrm{Mg}^{2+}\right)$ are shown in Fig. 6, which

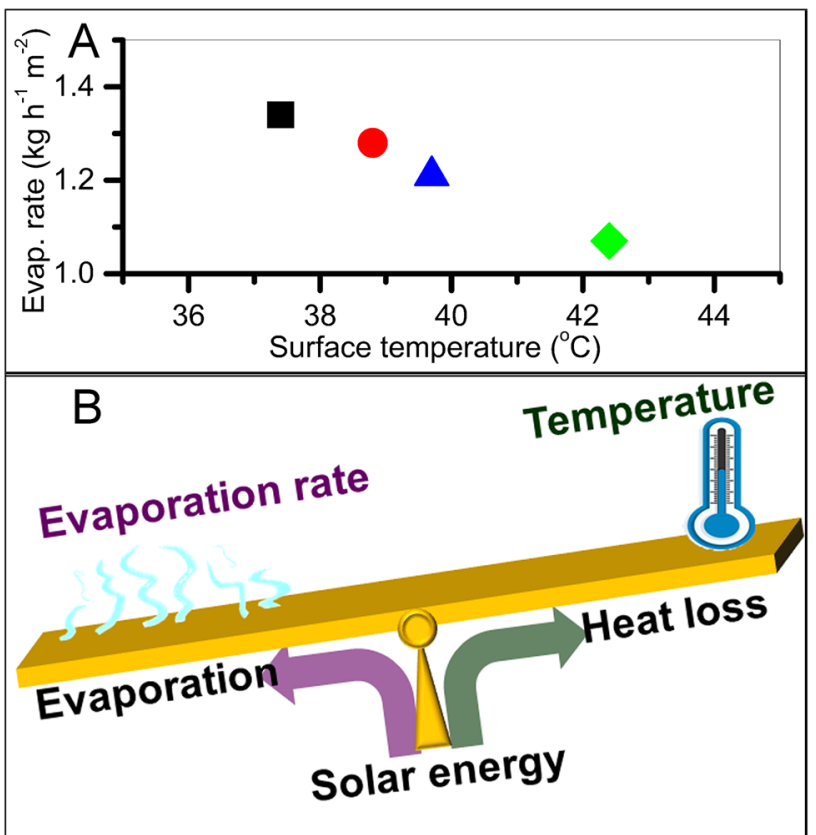

Fig. 5 a The evaporation on different papers at $1 \mathrm{~kW} \mathrm{~m}^{-2}$, where the add-on black square, blue triangle, red circle, and green diamond stand for results on the inked filter paper with pore size of $25,11,2.5 \mu \mathrm{m}$ and a transparent polyethylene covered $25 \mu \mathrm{m}$ filter paper, respectively; $\mathbf{b}$ the schematic balance of surface temperature and evaporation rate

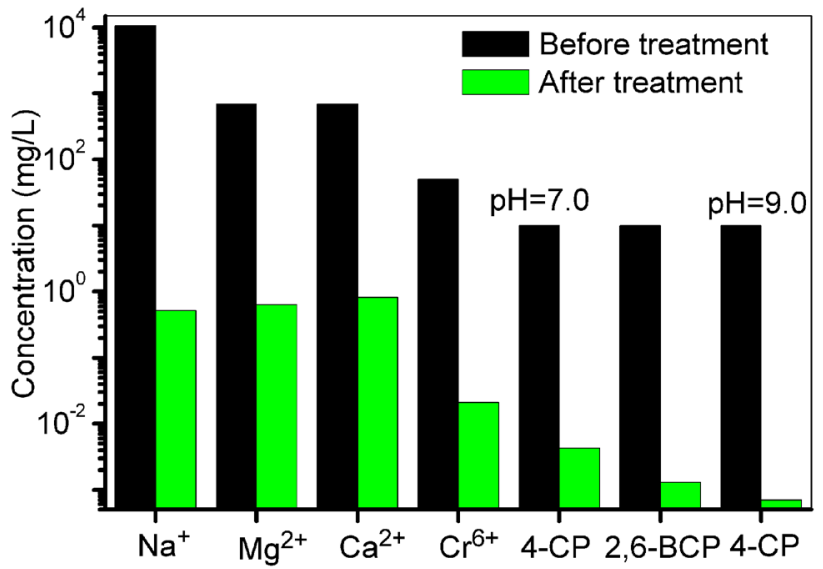

Fig. 6 The experiment results of saline water and wastewater treatment

is conducted in the cross-linked filter paper membrane evaporation-condensation system, and the condensate water was collected for ions concentration detection. After desalination, all the ionic concentrations dramatically decreased; especially, $\mathrm{Na}^{+}$ion concentration was about five orders of magnitude below the saline water. And these concentrations are far below the Chinese government drinking water standards (GB5749-2006). At the same time, 
we prepared a heavy metal $\mathrm{Cr}^{6+}$ pollutant with a $50 \mathrm{mg}$ $\mathrm{L}^{-1}$ ion solution for treatment. After evaporation, there are low concentrations of $\mathrm{Cr}^{6+}$ ions $\left(0.021 \mathrm{mg} \mathrm{L}^{-1}\right)$ in the condensate water, which meets the Chinese government drinking water standard (GB 5749-2006). These results indicated the effective removal of inorganic metal ions. We also investigate the removal of organic compounds such as chlorophenols in the solar evaporation system. Chlorophenols are a kind of important organic intermediates, which has strong toxicity and anti-degradation ability. They can cause problems in blood, liver and central nervous system, which seriously threaten human health and have been listed as pollutants that need priority treatment by the United Nations Environment Programme (UNEP). But conventional processes such as advance oxidation and biological treatment hardly remove it [36-38]. The solar evaporation treatment results are shown in Fig. 6. It can be seen the concentration of 4-chlorophenol decreased from 10 to $0.043 \mathrm{mg} \mathrm{L}^{-1}$ after treatment. And 4-chlorophenol removal is much higher under high $\mathrm{pH}$ value (9.0), because the phenol salt with higher boiling point can be formed under high $\mathrm{pH}$ value. Interestingly, the removal of 2,6-bichlorophenol is much higher than that of 4-chlorophenol unlike the chemical treatment method. The concentration of organic pollution in the condensation water is much lower than that limited by the Chinese drinking water standard (GB 5749-2006). These results show the good performance of nanoink filter paper in desalination and wastewater treatment for freshwater.

\section{Conclusion}

Photothermal evaporation of water using porous materials with strong light absorption is a promising way for water purification with low energy input. A hierarchically porous material with nanoporous carbon film and microporous paper has been developed for highly efficient photothermal water evaporation. The porous material is unique for three reasons: (1) packing of uniformly sized carbon nanoparticles contained in well-dispersed colloid ink can create nanoporous carbon film with large surface area and superior (blackbody like) light absorption over a wide wavelength range; (2) paper with micrometer thickness and low thermal conductivity decreases thermal loss to environment or water reservoir and allows continuous water transport through micropores; and (3) low-cost ink and paper materials and straightforward modification allow this method to be scaled up easily. An energy efficiency of over $90 \%$ with evaporating rate of $1.34 \mathrm{~kg} \mathrm{~m}^{-2} \mathrm{~h}^{-1}$ has been achieved on carbon nanoparticle modified paper with pore size of $25 \mu \mathrm{m}$ at energy intensity of $1 \mathrm{~kW} \mathrm{~m}^{-2}$. It was also explored to saline water and polluted water treatment, and safe freshwater can be obtained after photothermal membrane purifying.

Acknowledgements The work has been supported by National Science Foundation (NSF) through Grant No. 1602984 and a Visiting Scholar Project from Tianjin Normal University Innovation Promotion Plan (135202XC1601).

\section{Compliance with ethical standards}

Conflict of interest The authors declare that they have no known competing financial interests or personal relationships that could have appeared to influence the work reported in this paper.

\section{References}

1. Chandrashekara M, Yadav A (2017) Water desalination system using solar heat: a review. Renew Sustain Energy Rev 67:1308-1330

2. Gude VG (2015) Energy storage for desalination processes powered by renewable energy and waste heat sources. Appl Energy 137:877-898

3. Li XQ, Xu WC, Tang MY, Zhou L, Zhu B, Zhu SN, Zhu J (2016) Graphene oxide-based efficient and scalable solar desalination under one sun with a confined 2D water path. Proc Natl Acad Sci U S A 113(49):13953-13958

4. Lin M, Reinhold J, Monnerie N, Haussener S (2018) Modeling and design guidelines for direct steam generation solar receivers. Appl Energy 216:761-776

5. Neumann O, Feronti C, Neumann AD, Dong AJ, Schell K, Lu B, Kim E, Quinn M, Thompson S, Grady N, Nordlander P, Oden M, Halas NJ (2013) Compact solar autoclave based on steam generation using broadband light-harvesting nanoparticles. Proc Natl Acad Sci U S A 110(29):11677-11681

6. Zhou L, Tan YL, Wang JY, Xu WC, Yuan Y, Cai WS, Zhu SN, Zhu J (2016) 3D self-assembly of aluminium nanoparticles for plasmon-enhanced solar desalination. Nat Photonics 10(6):393-398

7. Zhu LL, Gao MM, Peh CKN, Wang XQ, Ho GW (2018) Self-contained monolithic carbon sponges for solar-driven interfacial water evaporation distillation and electricity generation. Adv Energy Mater 8(16):1870074-1870082

8. Ghasemi H, Ni G, Marconnet AM, Loomis J, Yerci S, Miljkovic N, Chen G (2014) Solar steam generation by heat localization. Nat Commun 5:1-7

9. Siddique $\mathrm{M}$, Turkmen N, Al-Rabghi OM, Shabana E, Albeirutty MH (2018) Small-scale low pressure 'single effect distillation' and 'single stage flash' solar driven barometric desalination units: a comparative analysis. Desalination 444:53-62

10. Gonzalez-Roubaud E, Perez-Osorio D, Prieto C (2017) Review of commercial thermal energy storage in concentrated solar power plants: steam versus molten salts. Renew Sustain Energy Rev 80:133-148

11. Zhang GQ, LiYY, Zhang N (2017) Performance analysis of a novel low $\mathrm{CO}_{2}$-emission solar hybrid combined cycle power system. Energy 128:152-162

12. Wu X, Chen GY, Owens G, Chu D, Xu H (2019) Photothermal materials: a key platform enabling highly efficient water evaporation driven by solar energy. Mater Today Energy 12:277-296

13. Bilgil A, Hirlakoglu B (2017) An experimental study on desalination at vacuum environment under low pressure and low condensation temperatures. Desalination 411:9-18 
14. Islam MT, Huda N, Abdullah AB, Saidur R (2018) A comprehensive review of state-of-the-art concentrating solar power (CSP) technologies: current status and research trends. Renew Sustain Energy Rev 91:987-1018

15. Yi LC, Ci SQ, Luo SL, Shao P, Hou Y, Wen ZH (2017) Scalable and low-cost synthesis of black amorphous $\mathrm{Al}-\mathrm{Ti}-\mathrm{O}$ nanostructure for high-efficient photothermal desalination. Nano Energy 41:600-608

16. Politano A, Argurio P, Di Profio G, Sanna V, Cupolillo A, Chakraborty S, Arafat HA, Curcio E (2017) Photothermal membrane distillation for seawater desalination. Adv Mater 29(2):1603504-1603510

17. Tao P, Ni G, Song C, Shang W, Wu J, Zhu J, Chen G, Deng T (2018) Solar-driven interfacial evaporation. Nat Energy 3:1031-1041

18. Wu X, Robson ME, Phelps JL, Tan JS, Shao B, Owens G, Xua HL (2019) A flexible photothermal cotton-CuS nanocage-agarose aerogel towards portable solar steam generation. Nano Energy 56:708-715

19. Wu X, Gao T, Han CH, Xu JS, Owens Owens G, Xua HL (2019) A photothermal reservoir for highly efficient solar steam generation without bulk water. Sci Bull 64:1625-1633

20. Zong L, Li MJ, Li CX (2018) Intensifying solar-thermal harvest of low-dimension biologic nanostructures for electric power and solar desalination. Nano Energy 50:308-315

21. Kaur M, Ishii S, Shinde SL, Nagao T (2017) All-ceramic microfibrous solar steam generator: TiN plasmonic nanoparticleloaded transparent microfibers. ACS Sustain Chem Eng 5(10):8523-8528

22. Alsharief $A$, Mustafa I, AINahyan $M$, Alnaqbi W, Almarzooqi $F$ (2020) CNT-PVDF freestanding sheets for direct solar evaporation toward continuous desalination applications. J Mater Sci 55(7):2860-2869

23. Sui YJ, Hao DD, Guo Y, Cai ZS, Xu B (2020) A flowerlike sponge coated with carbon black nanoparticles for enhanced solar vapor generation. J Mater Sci 55(1):298-308

24. Liu KK, Jiang Q, Tadepallifit S, Raliya R, Biswas P, Naik RR, Singamaneni S (2017) Wood graphene oxide composite for highly efficient solar steam generation and desalination. ACS Appl Mater Interfaces 9(8):7675-7681

25. Yang YB, Yang XD, Fu LN, Zou MC, Cao AY, Du YP, Yuan Q, Yan $\mathrm{CH}$ (2018) Two-dimensional flexible bilayer janus membrane for advanced photothermal water desalination. ACS Energy Lett 3(5):1165-1171

26. Hu XZ, Xu WC, Zhou L, Tan YL, Wang Y, Zhu SN, Zhu J (2017) Tailoring graphene oxide-based aerogels for efficient solar steam generation under one sun. Adv Mater 29(5):1604031-1604037
27. Finnerty C, Zhang L, Sedlak DL, Nelson KL, Mi BX (2017) Synthetic graphene oxide leaf for solar desalination with zero liquid discharge. Environ Sci Technol 51(20):11701-11709

28. Ren HY, Tang M, Guan BL, Wang KX, Yang JW, Wang FF, Wang MZ, Shan JY, Chen ZL, Wei D, Peng HL, Liu ZF (2017) Hierarchical graphene foam for efficient omnidirectional solar-thermal energy conversion. Adv Mater 29(38):1702590-1702597

29. Yang Y, Zhao RQ, Zhang TF, Zhao K, Xiao PS, Ma YF, Ajayan PM, Shi GQ, Chen YS (2018) Graphene-based standalone solar energy converter for water desalination and purification. ACS Nano 12(1):829-835

30. Fu Y, Wang G, Mei T, Li JH, Wang JY, Wang XB (2017) Accessible graphene aerogel for efficiently harvesting solar energy. ACS Sustain Chem Eng 5(6):4665-4671

31. Zhu LL, Gao MM, Peh CKN, Ho GW (2018) Solar-driven photothermal nanostructured materials designs and prerequisites for evaporation and catalysis applications. Mater Horizons 5(3):323-343

32. Liu GH, Xu JL, Wang KY (2017) Solar water evaporation by black photothermal sheets. Nano Energy 41:269-284

33. Manokar AM, Murugavel KK, Esakkimuthu G (2014) Different parameters affecting the rate of evaporation and condensation on passive solar still-a review. Renew Sustain Energy Rev 38:309-322

34. Yang H-C, Chen Z, Xie Y, Wang J, Elam JW, Li W, Darling SB (2019) Chinese ink: a powerful photothermal material for solar steam generation. Adv Mater Interfaces 6(1):1801252-1801259

35. Ni G, Li G, Boriskina SV, Li HX, Yang WL, Zhang TJ, Chen G (2016) Steam generation under one sun enabled by a floating structure with thermal concentration. Nat Energy 1:1-7

36. Dai Q, Ma L, Ren N, Ning P, Guo Z, Xie L (2019) Research on the variations of organics and heavy metals in municipal sludge with additive acetic acid and modified phosphogypsum. Water Res 155:42-55

37. Zhang KF, Yong F, McCarthy DT, Deletic A (2018) Predicting long term removal of heavy metals from porous pavements for stormwater treatment. Water Res 142:236-245

38. Wang $Y$, Sun MX, Fang YL, Sun SF, He J (2016) $\mathrm{Ag}_{2} \mathrm{~S}$ and $\mathrm{MoS}_{2}$ as dual, co-catalysts for enhanced photocatalytic degradation of organic pollutions over CdS. J Mater Sci 51(2):779-787

Publisher's Note Springer Nature remains neutral with regard to jurisdictional claims in published maps and institutional affiliations. 